\title{
The value of epithelial cell stable free body of iron protoporphyrin reduced state detection in the diagnosis of cervical cancer.
}

\author{
Jimin Ma', Cuiqing Chai ${ }^{2}$, Yuqing Liu ${ }^{1}$, Mei Song ${ }^{3}$, Zhenhua Yin ${ }^{4}$, Aihua $\mathrm{Li}^{5 *}$ \\ ${ }^{1}$ Department of Obstetrics and Gynecology, Liaocheng Third People's Hospital, PR China \\ ${ }^{2}$ Department of Pathology, Liaocheng Third People's Hospital, PR China \\ ${ }^{3}$ Department of Obstetrics and Gynecology, Yizheng People's Hospital of Jiangsu Province, PR China \\ ${ }^{4}$ Department of Obstetrics and Gynecology, Shenxian people's Hospital of Shandong, PR China \\ ${ }^{5}$ Department of Obstetrics and Gynecology, Liaocheng People's Hospital, PR China
}

\begin{abstract}
Cervical cancer is one of the most common malignant tumors in female only second to breast cancer. There are several methods for cervical cancer screening. Free body of iron protoporphyrin reduced state (FH) is used in the screening of cervical intraepithelial neoplasia in different stages. However, there is still lack of investigation about the diagnostic value of epithelial cell stable $\mathrm{FH}$ in cervical cancer. Epithelial cell FH staining kit was used to test epithelial cell FH. Pathology was selected as the golden standard for cervical cancer diagnosis. Sensitivity, specificity, accuracy, positive predictive value, and negative predictive value were calculated. Receiver Operating Characteristic (ROC) curve was adopted to analyse the diagnostic value of FH on cervical cancer. The detection sensitivity of $\mathrm{FH}$ was different in Cervical Intraepithelial Neoplasia (CIN) at different stages. Sensitivity was higher, while specificity was lower following malignancy upgrading. Combining correct index and Kappa value, FH showed great diagnostic value for CIN and cervical cancer with different malignant potential. Area Under the Curve (AUC) of FH on CIN I, CIN II, CIN III, and cervical squamous cell carcinoma was $0.761,0.825,0.815$, and 0.877 , respectively $(\mathrm{P}<0.01)$. Epithelial cell stable $\mathbf{F H}$ detection was an important supplementary mean for cervical cancer diagnosis.
\end{abstract}

Keywords: Epithelial cell stability, FH, Cervical cancer, Diagnostic value.

Accepted on October 24, 2017

\section{Introduction}

Cervical cancer is one of the most common malignant tumors in female only second to breast cancer. It is usually caused by Human Papilloma Virus (HPV) infection [1]. Cervical cancer seriously influences women health and quality of life [2,3]. There are 530,000 new cases and 275,000 death cases every year [4]. Due to the lack of cervical cancer screening method, it has become a serious burden of society in developing country. Its incidence is still rising especially in rural areas [5]. Cervical Intraepithelial Neoplasia (CIN), as the precancerous lesion of cervical cancer, is closely related to the cervical invasive cancer [6]. It most often occurs in women aged 25 to 35. Low-level CIN can spontaneous regress, while high-level $\mathrm{CIN}$ has the cancerous potential. Different degrees of CIN can reflect the continuous development process of the cervical cancer. A large amount of literatures confirmed the long time needed from CIN to invasive cancer. Therefore, efficient screening for precancerous lesion and early stage cervical cancer, together with effective treatment, can significantly reduce the morbidity and mortality of cervical cancer [7].

Currently, the screening methods commonly used for cervical cancer include cervical liquid based cytology, and HPV screening, and macroscopic observation, etc. However, different detection methods have their own disadvantages [8]. Cervical liquid based cytology and HPV screening are the most commonly used methods in clinic. Cervical liquid based cytology usually needs rich experienced and high technology, whereas it still has high rate of missed diagnosis. HPV screening is featured as complicated process and higher cost.

Carcinogenic factors make the normal cells lose homeostasis and change the enzyme protein conformation, resulting in ferroheme precipitation and FH appear [9]. Thus, patients with malignant tumor usually appear FH level elevation. Researchers have developed the related detection kit. As a new method for screening, FH detection is characterized as low cost, simple operation, and existing clinical data. This study 
analysed the diagnostic efficiency of FH detection in cervical cancer and precancerous lesions.

\section{Materials and Methods}

\section{General information}

A total of 100 cases of female received cervical cancer screening between May 2015 and Oct 2016 in Liaocheng Third People's Hospital were enrolled. The 70 cases with abnormal pathology result by vaginoscopy were selected as observation group with mean age at $41.2 \pm 7.8$ (18-59 y old). The 30 cases with normal pathology confirmed by vaginoscopy with mean age at $40.9 \pm 5.7$ (19-57 y old) were grouped as control. This study was approved by the ethics committee and all the subjects had signed informed consent.

\section{Inclusion and exclusion criteria}

Inclusion criteria: 1. patient was not in gestation, stegmonth, or menstrual period; 2 . patient was not in acute genital tract inflammation; 3. patient received no cervical physiotherapy.

Exclusion criteria: 1. patient in menstrual period; 2. patient with lesions that may lead to false positive result, such as intermenstrual bleeding, cervical polyp, severe cervical erosion, cervical ulcer, cervical trauma, and submucosal uterine fibroids.

\section{Cervical epithelial cell stable FH detection}

A cervical exudatives sampler was slowly inserted to the cervical part through the vagina and scrubbed the cervix at the sequence of upper right, lower right, lower left, and upper left. The exudatives were put into the specimen bottle and mixed up. The sample was tested using the epithelial cell $\mathrm{FH}$ detection kit (Defmelo, Qingdao, China) according to the manual. The color was observed and compared with the shade guide. Judgement criteria: non-staining was negative, referring to good epithelial cell stability; pale bluish green was probable positive, referring to slightly poor epithelial cell stability; wathet was weak positive, referring to poor epithelial cell stability; blue was positive, referring to epithelial cell instability; mazarine was strong positive, referring to extremely unstable epithelial cell. The change of mazarine to deep yellow or brownish red indicated blood in the sample, and was also considered as strong positive. FH positive was defined as stronger than weak positive.

\section{Cervical pathological examination}

Pathological examination was performed on acetic acid test abnormal area and iodine test unstaining area. The cervical squamous-column junction was regularly biopsied at 3, 6, 9, and 12 points. The tissue was routinely treated by paraffin section, HE staining, and microscopic observation. The slice was read by the pathologist. The lesions were divided into normal, CIN I, CIN II, CIN III, and cervical cancer. The lesions over CIN I was considered as biopsy positive.

\section{Statistical analysis}

SPSS 16.0 software was used for data analysis. Data were presented as mean \pm Standard Deviation (SD). Chi-square test was performed for comparison of the difference of categorical data and student t-test was used for difference comparison of measurement data between two groups. A significant difference was considered if $\mathrm{P}<0.05$. Receiver Operating Characteristic (ROC) curve was adopted to analyse the diagnostic value of FH on cervical cancer. The sensitivity was calculated using this formula: sensitivity=number of true positive assessment/number of all positive assessment. Specificity was calculated as: specificity $=$ number of true negative assessment/number of all negative assessment.

\section{Results}

\section{General information comparison}

The clinical information was collected. No statistical significance was observed between two groups, such as age, blood pressure, heart rate, BMI, and degree of education (Table 1).

\section{Cervical FH detection}

Epithelial cell FH staining kit was used to test epithelial cell FH. Pathology was selected as the golden standard for cervical cancer diagnosis. Sensitivity, specificity, accuracy, positive predictive value, and negative predictive value were calculated. The consistency of the different degrees of CIN and pathologic result (kappa value) was listed in Table 2. The detection sensitivity of $\mathrm{FH}$ was different in Cervical Intraepithelial Neoplasia (CIN) at different stages. Sensitivity was higher, while specificity was lower following malignancy upgrading. Combining correct index and Kappa value, FH showed great diagnostic value for CIN and cervical cancer with different malignant potential.

\section{Cervical pathological HE staining}

HE staining showed that the normal cervix was composed of squamous epithelium and columnar epithelium, together with clear cell division and regular pattern of arrangement. The cell nucleus exhibited atypia, enlargement, and deep staining following the progress of CIN. Cervical cancer showed squamous epithelial cell hyperplasia with irregular arrangement (Figure 1).

\section{ROC curve analysis}

ROC curve was an important tool to predict the diagnostic value of the index. It was found that the Area Under the Curve (AUC) of FH on CIN I, CIN II, CIN III, and cervical squamous cell carcinoma was $0.761,0.825,0.815$, and 0.877 , respectively $(\mathrm{P}<0.01)$ (Figure 2). Therefore, $\mathrm{FH}$ detection had significant diagnostic value for CIN II, CIN III, and cervical cancer. 

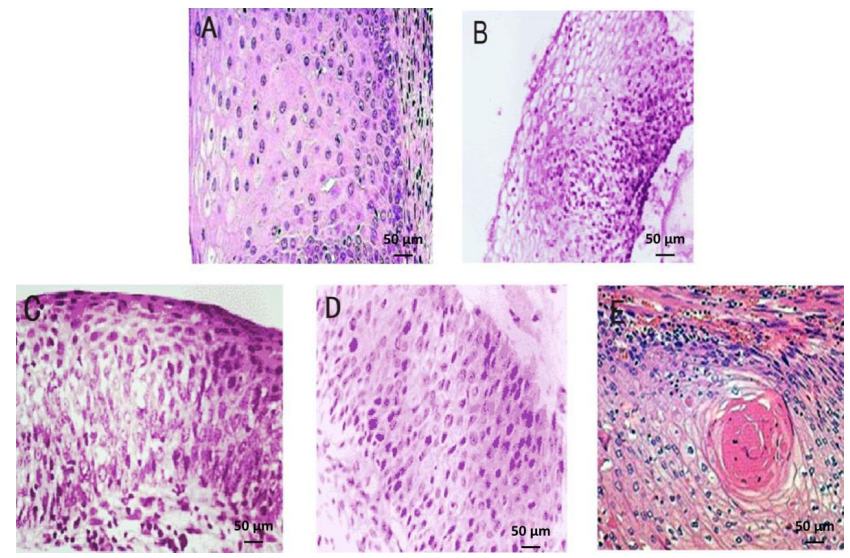

Figure 1. Cervical HE staining (X20). A, normal cervical epithelium; B: CIN I; C: CIN II; D: CIN III; E: cervical cancer. The cervical squamous-column junction was regularly biopsied at 3, 6, 9, and 12 points. The tissue was routinely treated by paraffin section followed by $H$ and E staining, and microscopic observation. The slice was read by the pathologist. Scale bar: $50 \mu \mathrm{m}$.
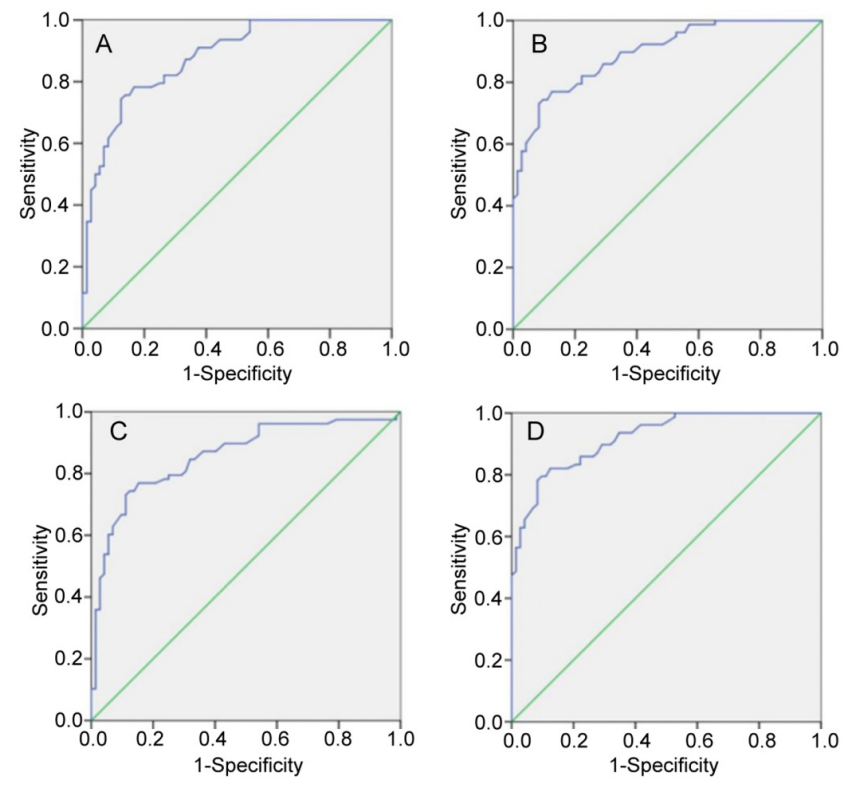

Figure 2. ROC curve analysis in different degree of CIN. A: CIN I; B: CIN II; C: CIN III; D: cervical cancer.

Table 1. General information.

\begin{tabular}{|c|c|c|c|}
\hline Index & $\begin{array}{l}\text { Observation group } \\
\text { (70) }\end{array}$ & Control (30) & $\begin{array}{l}P \\
\text { value }\end{array}$ \\
\hline Age (year) & $41.2 \pm 7.8$ & $40.9 \pm 5.7$ & 0.35 \\
\hline Systolic pressure (mmHg) & $135.32 \pm 8.45$ & $132.45 \pm 10.21$ & 0.06 \\
\hline Diastolic pressure $(\mathrm{mmHg})$ & $79.01 \pm 4.32$ & $78.21 \pm 5.43$ & 0.31 \\
\hline Heart rate (beat/min) & $85.32 \pm 8.96$ & $83.21 \pm 6.75$ & 0.11 \\
\hline BMI $\left(\mathrm{kg} / \mathrm{m}^{2}\right)$ & $22.5 \pm 2.5$ & $23.4 \pm 2.1$ & 0.09 \\
\hline \multicolumn{4}{|l|}{ Education } \\
\hline $\begin{array}{l}\text { Senior high school and the } \\
\text { following }\end{array}$ & 30 & 13 & 0.98 \\
\hline
\end{tabular}

\begin{tabular}{lll}
\hline Junior college & 21 & 9 \\
\hline Bachelor or above & 19 & 8 \\
\hline
\end{tabular}

\section{Discussion}

Cervical cancer is a common cancer only second only to breast cancer. Multiple etiological studies showed that HPV infection was closely associated with cervical cancer $[10,11]$. CIN is the precancerous lesions of cervical cancer. About 6-8 y is needed for CIN developing to cervical cancer [12]. This period provides sufficient time for cervical cancer screening. The application of various screening methods reduces the morbidity and mortality of cervical cancer. Searching for simple and efficient screening method is the important guarantee for cervical cancer treatment.

Macroscopic observation is clinical used method for screening. However, limited by technology and experience, it usually causes low sensitivity and high rate of the missed diagnosis in early stage patients. Following the progress of detection technology, this method is gradually replaced by other approaches. HPV detection has relative high sensitivity. Positive patients also exhibit higher risk of suffering from cervical cancer. HPV DNA detection has been widely used in clinic and has been treated as routine indicator in the developed countries $[13,14]$. However, its high cost and long period limits its popularization [15]. Colposcopy examination is also a method for cervical cancer screening, while it cannot accurately assess the lesions. Cytology and pathology examinations are needed for assistance. Cervical exfoliated cytology is the main method used to find precancerous lesions $[16,17]$. However, it is highly subjective and requires higher technique.

FH widely exists in each cell, especially in mitochondria. FH plays different physiological functions by binding with different proteins [18]. The occurrence of tumor is usually the outcome of multiple factors' synergy, such as the activation of proto-oncogenes and inactivation of tumor suppressor gene [19]. Under the pathological conditions, such as abnormal DNA transcription, disruption of the tight regulation of gene expression, as well as changes of protein conformation, $\mathrm{FH}$ will be exuded from the cellular protein, making cell loss of homeostasis and canceration through a series of electronic reactions.

The occurrence and development of malignant tumor is usually from benign hyperplasia to precancerous lesions and metastatic carcinoma [20]. As the cell damage aggravation, proteolytic enzyme causes cell autolysis, leading to FH substance exudation. The amount of $\mathrm{FH}$ exudation was in direct proportion with epithelial cell malignancy. Therefore, FH could be used to quantitatively evaluate the malignant lesions. At present, FH reacts with substance to form blue sediment, whose coloring degree is used for malignancy judgement. FH is a new method for cervical cancer screening. Meanwhile, $\mathrm{FH}$ detection kit is featured as simple operation and low cost. Therefore, it is suitable for clinical screening of cervical cancer, especially in poverty-stricken area and primary 
hospital. Moreover, it was found that FH combining TCT showed relative high value for cervical lesions screening [21].

This study found that the detection sensitivity of FH was different in CIN at different stages. Following malignancy upgrading, the sensitivity was higher, resulting in lower specificity. Combining correct index and Kappa value, $\mathrm{FH}$ showed great diagnostic value for CIN and cervical cancer with different malignant potential. It indicated that $\mathrm{FH}$ detection can reach the cytological sensitivity and specificity. AUC of FH on CIN I, CIN II, CIN III, and cervical squamous cell carcinoma was $0.761,0.825,0.815$, and 0.877 , respectively. It speculated that $\mathrm{FH}$ detection showed great diagnostic value for CIN II, CIN III, and cervical squamous cell carcinoma. FN detection can also obtain result at the same time of gynecologic examination, which is convenient and has high application value. However, since it is only a qualitative method, other approaches are needed to evaluate the malignant degree. Considering its value, it is a feasible method for population screening.

Table 2. Diagnostic analysis of FH on different degrees of CIN and cervical cancer.

\begin{tabular}{|c|c|c|c|c|c|c|c|c|}
\hline Grade & Sensitivity & Specificity & Correct index & $\begin{array}{l}\text { Positive } \\
\text { value }\end{array}$ & predictive & $\begin{array}{l}\text { Negative } \\
\text { value }\end{array}$ & predictive & Kappa value \\
\hline CIN I & $79.30 \%$ & $88.10 \%$ & $66.40 \%$ & $86.10 \%$ & & $79.30 \%$ & & $72.50 \%$ \\
\hline CIN II & $81.20 \%$ & $87.30 \%$ & $68.50 \%$ & $78.40 \%$ & & $85.90 \%$ & & $81.40 \%$ \\
\hline CIN III & $83.10 \%$ & $79.70 \%$ & $62.80 \%$ & $76.90 \%$ & & $83.40 \%$ & & $84.50 \%$ \\
\hline Cervical cancer & $83.20 \%$ & $82.40 \%$ & $65.60 \%$ & $90.10 \%$ & & $59.60 \%$ & & $83.20 \%$ \\
\hline
\end{tabular}

\section{Conclusion}

$\mathrm{FH}$ is a rapid screening method featured as convenience, fast, and cheap. However, as a new approach for cervical cancer screening, FH detection can only provide the qualitative detection and primary classification for cervical lesion. It cannot classify the pathological type, thus can only be used for screening.

\section{References}

1. Walboomers JM, Jacobs MV, Manos MM, Bosch FX, Kummer JA, Shah KV, Snijders PJ, Peto J, Meijer CJ, Munoz N. Human papillomavirus is a necessary cause of invasive cervical cancer worldwide. J Pathol 1999; 189: 12-19.

2. Xie Y, Zhao FH, Lu SH, Huang H, Pan XF, Yang CX, Qiao YL. Assessment of quality of life for the patients with cervical cancer at different clinical stages. Chin J Cancer 2013; 32: 275-282.

3. Sousa AM, Teixeira CC, Medeiros SD, Nunes SJ, Salvador PT, Barros RM, Lima FF, Nascimento GG, Santos JD, Souza DL, Bezerra AP, Meira KC. Cervical cancer mortality in the state of Rio Grande do Norte, Brazil, 1996-2010: time trends and projections up to 2030 Epidemiol Serv Saude 2016; 25: 311-322.

4. Ferlay J, Shin HR, Bray F, Forman D, Mathers C, Parkin DM. Estimates of worldwide burden of cancer in 2008: GLOBOCAN 2008. Int J Cancer 2010; 127: 2893-2917.

5. Wang J, Bai Z, Wang Z, Yu C. Comparison of secular trends in cervical cancer mortality in China and the united states: an age-period-cohort analysis. Int J Environ Res Public Health 2016; 13.
6. Martin-Hirsch PP, Paraskevaidis E, Bryant A, Dickinson HO, Keep SL. Surgery for cervical intraepithelial neoplasia. Cochrane Database Syst Rev 2010: 001318.

7. Perkins AC, Skinner EN. A review of the current cervical cancer screening guidelines. N C Med J 2016; 77: 420-422.

8. Arbyn M, Ronco G, Cuzick J, Wentzensen N, Castle PE. How to evaluate emerging technologies in cervical cancer screening? Int J Cancer 2009; 125: 2489-2496.

9. Wu J, Wen S, Zhou Y, Chao H, Shen Y. Human ferrochelatase: insights for the mechanism of ferrous iron approaching into protoporphyrin IX by QM/MM and QTCP free energy studies. J Chem Inf Model 2016.

10. Balanda M, Quiero A, Vergara N, Espinoza G, Martin HS, Rojas G, Ramirez E. Prevalence of human papillomavirus infection among women presenting for cervical cancer screening in Chile, 2014-2015. Med Microbiol Immunol 2016; 205: 585-594.

11. Priebe AM. 2012 cervical cancer screening guidelines and the future role of HPV testing. Clin Obstet Gynecol 2013; 56: 44-50.

12. Ostor AG. Natural history of cervical intraepithelial neoplasia: a critical review. Int J Gynecol Pathol 1993; 12: 186-192.

13. Zhao FH, Lin MJ, Chen F, Hu SY, Zhang R, Belinson JL, Sellors JW, Franceschi S, Qiao YL, Castle PE, Cervical Cancer Screening Group in C. Performance of high-risk human papillomavirus DNA testing as a primary screen for cervical cancer: a pooled analysis of individual patient data from 17 population-based studies from China. Lancet Oncol 2010; 11: 1160-1171.

14. Li ZM, Zeng LQ, Peng XH, Mao LZ, Sun XL, Li YH, Luo XP. Analysis of clinical and pathological characteristics of high- risk HPV-negative carcinoma of the uterine cervix. Zhonghua Fu Chan Ke Za Zhi 2016; 51: 683-687. 
The value of epithelial cell stable free body of iron protoporphyrin reduced state detection in the diagnosis of cervical cancer

15.Zhang Q, Liu YJ, Hu SY, Zhao FH. Estimating long-term clinical effectiveness and cost-effectiveness of HPV 16/18 vaccine in China. BMC Cancer 2016; 16: 848.

16. Siebers AG, van der Laak JA, Huberts-Manders R, Vedder $\mathrm{JE}$, Bulten J. Accurate assessment of cell density in low cellular liquid-based cervical cytology. Cytopathology 2013; 24: 216-221.

17. Habbema D, Weinmann S, Arbyn M, Kamineni A, Williams AE, de Kok IM, van Kemenade F, Field TS, van Rosmalen J, Brown M. Harms of cervical cancer screening in the United States and the Netherlands. Int J Cancer 2016.

18. McCauley RA, Cortes-Palomec AC, Oyama K. Isolation, characterization, and cross-amplification of polymorphic microsatellite loci in Guaiacum coulteri (Zygophyllaceae). Mol Ecol Resour 2008; 8: 671-674.

19. Jiang P, Du W, Wang X, Mancuso A, Gao X, Wu M, Yang $X$. p53 regulates biosynthesis through direct inactivation of glucose-6-phosphate dehydrogenase. Nat Cell Biol 2011; 13: 310-316.
20.Zeng Q, Chen J, Li Y, Werle KD, Zhao RX, Quan CS, Wang YS, Zhai YX, Wang JW, Youssef M, Cui R, Liang J, Genovese N, Chow LT, Li YL, Xu ZX. LKB1 inhibits HPV-associated cancer progression by targeting cellular metabolism. Oncogene 2016.

21. Yu Qin Hu FQL, Yan Li Liu. Clinical diagnostic value of cells free ferrous protoporphyrin and thin-cytologic test for cervical lesions. Journal of Hebei Medical University 2016; 37: 35-39.

\section{*Correspondence to}

Aihua Li

Department of Obstetrics and Gynecology

Liaocheng People's Hospital

PR China 